\title{
Efficient itaconic acid production from glycerol with Ustilago vetiveriae TZ1
}

\author{
Thiemo Zambanini ${ }^{1}$, Hamed Hosseinpour Tehrani ${ }^{1}$, Elena Geiser ${ }^{1}$, Dorothee Merker ${ }^{1}$, Sarah Schleese , \\ Judith Krabbe ${ }^{1}$, Joerg M. Buescher ${ }^{2}$, Guido Meurer ${ }^{2}$, Nick Wierckx ${ }^{1 *}$ and Lars M. Blank ${ }^{1}$
}

\begin{abstract}
Background: The family of Ustilaginaceae is known for their capability to naturally produce industrially valuable chemicals from different carbon sources. Recently, several Ustilaginaceae were reported to produce organic acids from glycerol, which is the main side stream in biodiesel production.

Results: In this study, we present Ustilago vetiveriae as new production organism for itaconate synthesis from glycerol. In a screening of 126 Ustilaginaceae, this organism reached one of the highest titers for itaconate combined with a high-glycerol uptake rate. By adaptive laboratory evolution, the production characteristics of this strain could be improved. Further medium optimization with the best single colony, U. vetiveriae TZ1, in 24-deep well plates resulted in a maximal itaconate titer of $34.7 \pm 2.5 \mathrm{~g} \mathrm{~L}^{-1}$ produced at a rate of $0.09 \pm 0.01 \mathrm{~g} \mathrm{~L}^{-1} \mathrm{~h}^{-1}$ from $196 \mathrm{~g} \mathrm{~L}^{-1}$ glycerol. Simultaneously, this strain produced $46.2 \pm 1.4 \mathrm{~g} \mathrm{~L}^{-1}$ malate at a rate of $0.12 \pm 0.00 \mathrm{~g} \mathrm{~L}^{-1} \mathrm{~h}^{-1}$. Due to product inhibition, the itaconate titer in $\mathrm{NaOH}$-titrated bioreactor cultivations was lower $\left(24 \mathrm{~g} \mathrm{~L}^{-1}\right)$. Notably, an acidic $\mathrm{pH}$ value of 5.5 resulted in decreased itaconate production, however, completely abolishing malate production. Overexpression of ria 1 or $m t t 1$, encoding a transcriptional regulator and mitochondrial transporter, respectively, from the itaconate cluster of $U$. maydis resulted in a 2.0-fold (ria1) and 1.5-fold ( $m$ tt 1 ) higher itaconate titer in comparison to the wild-type strain, simultaneously reducing malate production by 75 and $41 \%$, respectively.
\end{abstract}

Conclusions: The observed production properties of U. vetiveriae TZ1 make this strain a promising candidate for microbial itaconate production. The outcome of the overexpression experiments, which resulted in reduced malate production in favor of an increased itaconate titer, clearly strengthens its potential for industrial itaconate production from glycerol as major side stream of biodiesel production.

Keywords: Adaptive laboratory evolution, Fed-batch cultivation, Glycerol, Itaconate, Ustilago vetiveriae

\section{Background}

The switch from a mainly petroleum to a sustainable bioeconomy has become omnipresent over the last years. Consequently, research is focusing on the development of biotechnological production processes, resulting in biochemicals able to compensate for petrochemicals. One group of these chemicals is organic acids, such as succinate, malate, or itaconate.

\footnotetext{
${ }^{*}$ Correspondence: nick.wierckx@rwth-aachen.de

${ }^{1}$ Institute of Applied Microbiology-iAMB, Aachen Biology

and Biotechnology-ABBt, RWTH Aachen University, Worringerweg 1,

52074 Aachen, Germany

Full list of author information is available at the end of the article
}

Especially the C5-dicarboxylic acid, itaconate, has gained great interest, due to a broad range of possible applications in different industries and technologies, such as in carbon fibers, rubber, anti-scaling polymers in water treatment, cement additives, surface active agents, plastics, and dye intermediates [1-3]. Additionally, it can be converted into different value-added molecules, due to its multiple functional groups [1] or be used for self-polymerization to poly-itaconate, which has the potential to replace a broad range of different polymers [4-6]. In 2004, itaconate was announced one of the top twelve building block chemicals, to be produced from renewable biomass, by the U.S. Department of Energy [1]. Even though the contemporary market for itaconate 
is rather small with about $41 \mathrm{kt} \mathrm{a}^{-1}$ in 2013, corresponding to a market value of approximately US\$ 74.5 million, it is predicted to reach US\$ 570 million by 2020 [7]. This huge increase in the expected market volume is based on the possibility to substitute existing chemicals, if an improved production process can be developed that would lower the price for itaconate.

Chemical synthesis of itaconate was first reported in 1836 [8-10] and in 1931, Aspergillus itaconicus was the first organism to be found to produce itaconate [11]. In contrast to many other chemicals, contemporary itaconate production is completely achieved by biotechnological processes [2]. These processes mainly rely on $A$. terreus strains. The first $A$. terreus strain producing itaconate was discovered in 1939 [12] and since then, the use of this organism has been investigated and improved intensively for the production of itaconic acid [13-15]. Over the years, many different organisms have been found to produce itaconate, including several species of Pseudozyma [16, 17], Ustilago [18-21], and different Candida [22] and Rhodotorula [23] species.

Many of these production strains are a member of the family of Ustilaginaceae, which is a promising fungal family for biotechnological applications [24-26]. Recently, the itaconate production pathway in $U$. maydis has been clarified, allowing for targeted metabolic engineering of itaconate production in this host $[27,28]$.

The family of Ustilaginaceae is generally known for combining natural production of different industrially relevant products, such as organic acids, polyols, and lipids from a broad range of substrates, with favorable characteristics for biotechnological processes, such as a yeast-like morphology, insensitivity to medium impurities and tolerance to high product titers $[4,19-21,24,25$, 29-35]. Especially, the broad substrate range attracted interest in this group of organisms. As plant pathogens, Ustilaginaceae are able to degrade a broad range of polymers from biomass, such as cellulose, hemicellulose, or xylan [36-39]. Recently, malate production from biodiesel-derived glycerol has been demonstrated with Ustilago trichophora TZ1 [40-42]. The use of glycerol as substrate for microbial conversion has been discussed frequently over the last years. In a follow-up study of the landmark 2004 DOE report [1], glycerol is still considered as one of the 10 most promising building blocks to be produced [43]. However, worldwide increasing biodiesel production has resulted in a huge side stream of (crude) glycerol, which makes up $10 \%(\mathrm{w} / \mathrm{v})$ of the total production. With 123 million tons of biodiesel per year predicted for 2016 [44], 19 million tons of crude glycerol will flood the market, further lowering the price, while simultaneously decreasing the profit margin for the biodiesel production process itself. Consequently, valorization of this huge waste-stream has been discussed intensively, resulting in several microbial production processes for different products starting from glycerol $[45,46]$.

Here we present $U$. vetiveriae TZ1 as promising production organism for organic acids from glycerol, reaching high total acid titers with itaconate and malate as the main products. Further, we demonstrate that by single overexpression of two different genes, the acid production profile can be drastically influenced in favor of itaconate.

\section{Results and discussion}

Submersed cultivation reveals $U$. vetiveriae as a promising itaconate producer

Recently, we reported on an $U$. trichophora strain, which was found in a broad screening of Ustilaginaceae, to naturally produce malate from glycerol [40]. The primary screening in this study was performed on agar plates with a $\mathrm{pH}$ indicator, only resulting in a qualitative indication of growth and semi-quantitative indication concerning total acid production. Due to the generally high malate production of many Ustilaginaceae [21], this method is less suited for finding producers of other organic acids such as itaconate. Consequently, we performed a complete screening of 126 Ustilaginaceae cultivated in 24-deep well plate liquid cultures [47] containing mTM with $50 \mathrm{~g} \mathrm{~L}^{-1}$ glycerol, $0.8 \mathrm{~g} \mathrm{~L}^{-1} \mathrm{NH}_{4} \mathrm{Cl}$, and $100 \mathrm{~g} \mathrm{~L}^{-1} \mathrm{CaCO}_{3}$. After $355 \mathrm{~h}$, the culture supernatants were initially evaluated for glycerol uptake (Fig. 1a) and strains with the highest glycerol uptake rate were selected for further analysis.

As reported previously for Ustilaginaceae [21, 40], a broad phenotypic distribution was observed. Some strains consumed all carbon, while others did not grow at all on glycerol (Fig. 1a). Although organic acid production was observed with a broad diversity, titers were generally low due to the low concentration of glycerol used. Hence, we chose the 24 strains with fastest glycerol uptake (indicated by the red box in Fig. 1a), to investigate in a second 24-deep well plate screening with a higher initial glycerol concentration of $100 \mathrm{~g} \mathrm{~L}^{-1}$ (Fig. 1b). From this screening, the six strains with best itaconate and malate production properties (Fig. 1b) and highest glycerol uptake (indicated by arrows in Fig. 1b) were chosen and cultivated in shake flasks containing $200 \mathrm{~g} \mathrm{~L}^{-1}$ glycerol. Only three of these strains, $U$. vetiveriae, $U$. xerochloae, and Sporisorium iseilematis-ciliati were able to produce itaconate, reaching a titer of $4.4 \pm 0.8,20.1 \pm 4.6$, and $8.5 \pm 1.8 \mathrm{~g} \mathrm{~L}^{-1}$, respectively, while all strains produced malate with titers between $10.5 \pm 0.7$ and $63.1 \pm 0.3 \mathrm{~g} \mathrm{~L}^{-1}$. Even though production rates and titers for itaconate are lower than for A. terreus [48] and P. antarctica [16] on glucose, they are rather high for wild-type strains, given the applied conditions, leaving space for improvement. 

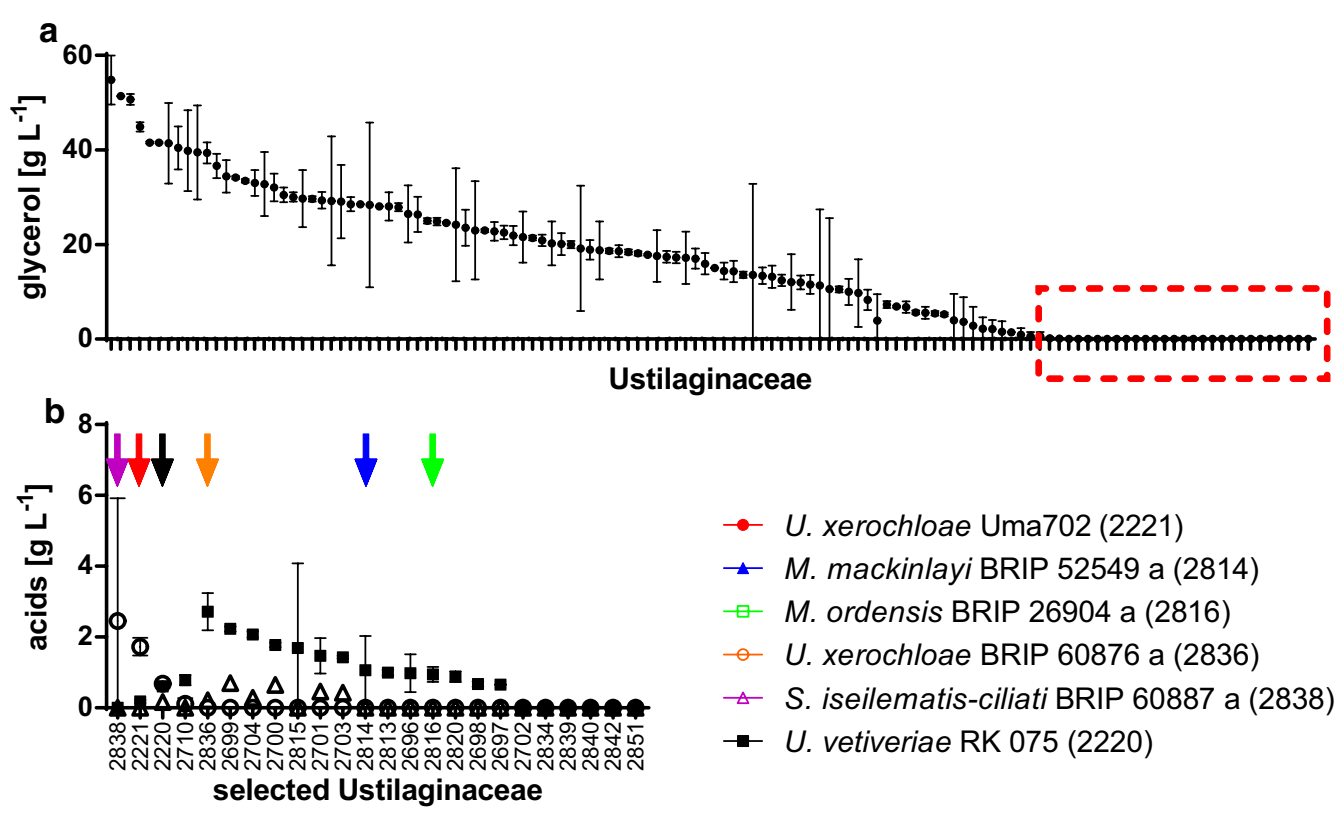

$\rightarrow \quad$ U. xerochloae Uma702 (2221)

$\rightarrow$ M. mackinlayi BRIP 52549 a (2814)

$\because \quad$ M. ordensis BRIP 26904 a (2816)

- U. xerochloae BRIP 60876 a (2836)

$\triangle$ S. iseilematis-ciliati BRIP 60887 a (2838)

$\rightarrow$ U. vetiveriae RK 075 (2220)
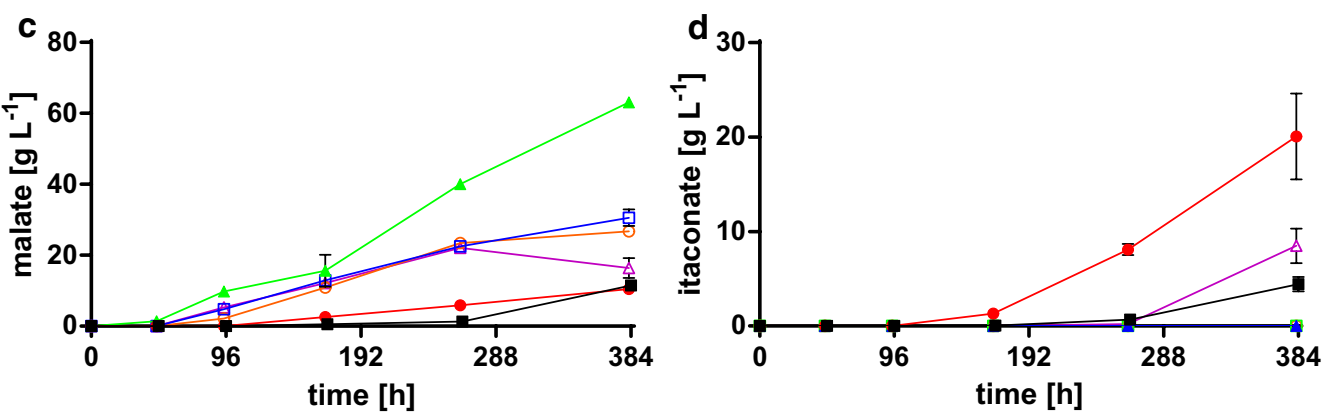

Fig. 1 Screening for the production of organic acids from glycerol. a Rank-ordered glycerol concentration after $355 \mathrm{~h}$ of cultivation in 24-deep well plates containing MTM with $50 \mathrm{~g} \mathrm{~L}^{-1}$ glycerol, $0.8 \mathrm{~g} \mathrm{~L}^{-1} \mathrm{NH}_{4} \mathrm{Cl}$, and $100 \mathrm{~g} \mathrm{~L}^{-1} \mathrm{CaCO}_{3}$ for 126 different Ustilaginaceae. The glycerol concentrations and strain numbers are indicated in Table 3. Strains with high-glycerol consumption (indicated by the red box) were re-screened for acid production. b Rank-ordered itaconate concentration (open circles), malate concentration (closed squares), and succinate concentration (open triangles) after $383 \mathrm{~h}$ of cultivation in 24-deep well plates containing MTM with $100 \mathrm{~g} \mathrm{~L}^{-1}$ glycerol, $0.8 \mathrm{~g} \mathrm{~L}^{-1} \mathrm{NH}_{4} \mathrm{Cl}$, and $100 \mathrm{~g} \mathrm{~L}^{-1} \mathrm{CaCO}_{3}$ for 24 selected Ustilaginaceae. Strains with good production (indicated by arrows) were evaluated in detail. c Malate concentration and $\mathbf{d}$ itaconate concentration for different Ustilaginaceae cultivated in shake flasks containing MTM with $200 \mathrm{~g} \mathrm{~L}^{-1}$ glycerol, $0.8 \mathrm{~g} \mathrm{~L}^{-1} \mathrm{NH}_{4} \mathrm{Cl}$, and $100 \mathrm{~g} \mathrm{~L}^{-1} \mathrm{CaCO}_{3}$. Error bars indicate deviation from the mean $(n=2)$

\section{Adaptive laboratory evolution improves growth and acid production on glycerol}

Adaptive laboratory evolution (ALE) is known to be suitable for the improvement of specific microbial characteristics by adaptation to the chosen environmental conditions and selection of beneficial mutations [49-51]. Recently, we were able to improve malate production, growth rate, and glycerol uptake in $U$. trichophora by ALE [40]. Here we used the same re-inoculation scheme in shake flasks applying faster growth rate and consequently higher glycerol uptake rates as selection pressure for all six strains from the last screening in duplicates. While growth rate could not be increased except for
$U$. vetiveriae, glycerol uptake was improved for all strains. Additionally, malate production was improved for all strains (Table 1). Figure 2a shows the results for $U$. vetiveriae RK075. Although the maximum glycerol uptake rate was not improved for this strain, the initial glycerol consumption was significantly improved by ALE, indicating an increased growth rate before the onset of nitrogen limitation.

Since the malate titers stayed below the titer reached with the previously published $U$. trichophora TZ1 [40, 41, 52] or A. oryzae [53, 54], we focused on the strains producing itaconic acid. However, none of the initially identified itaconate producers produced itaconate after the 


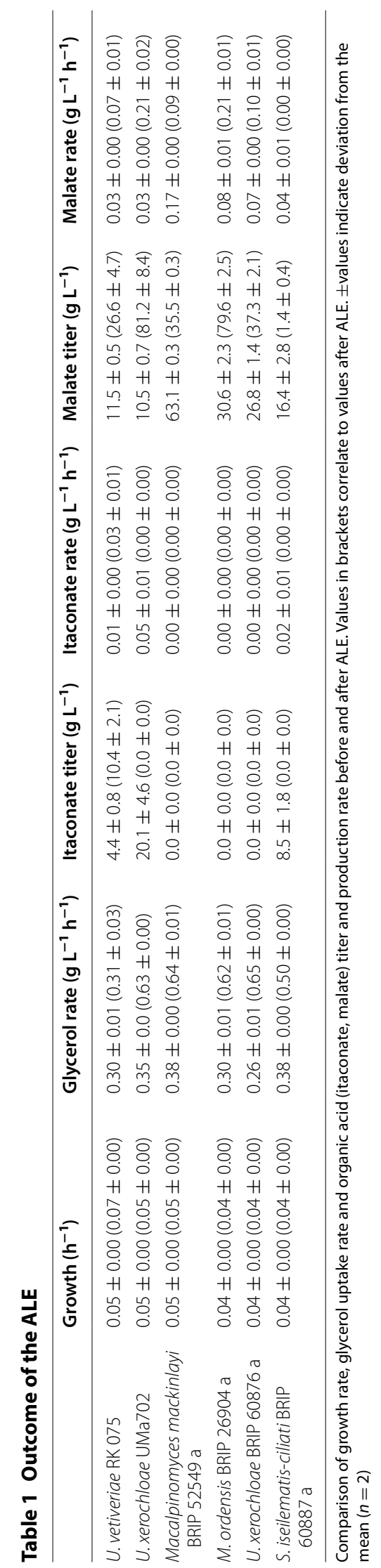



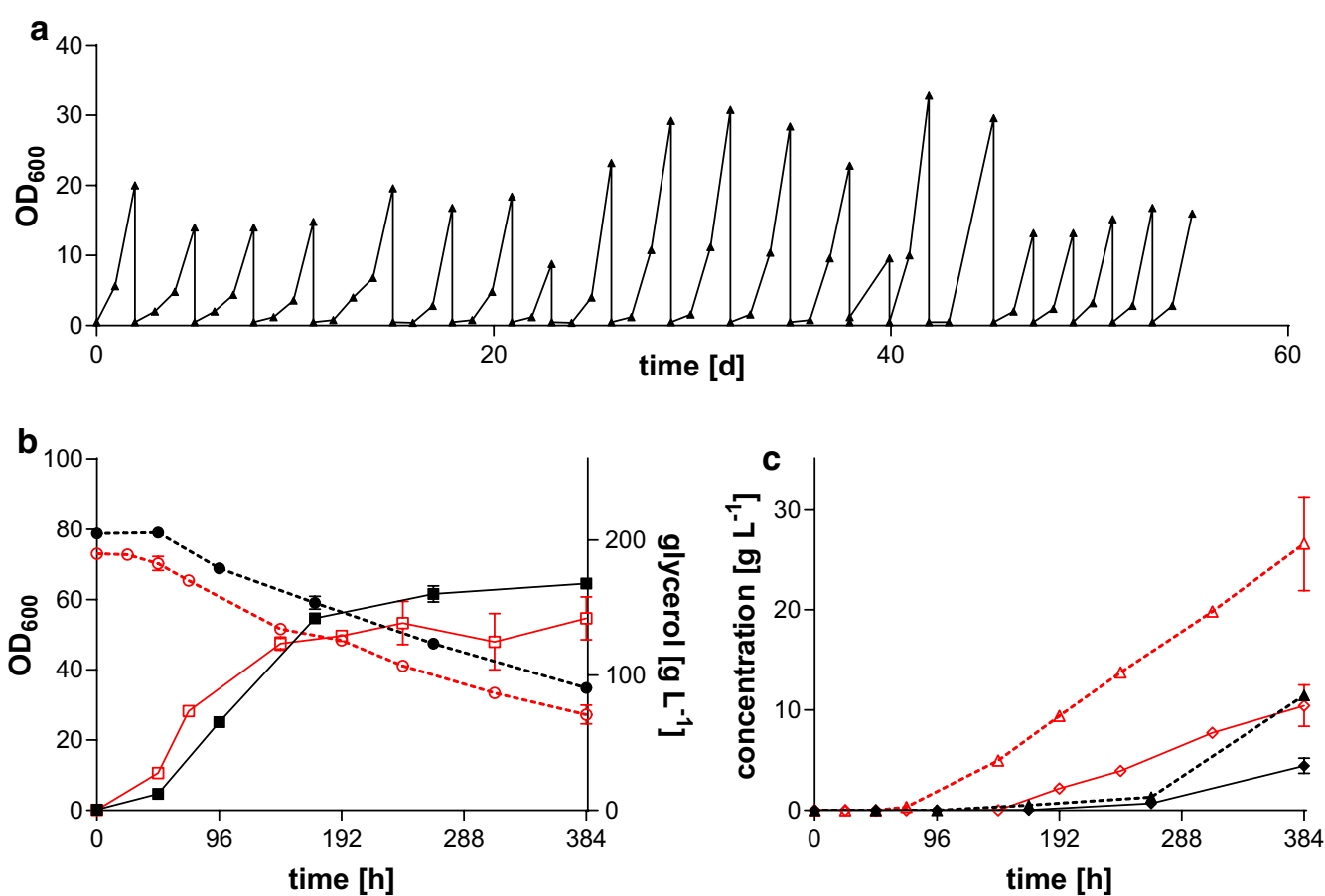

Fig. 2 Adaptive laboratory evolution of U. vetiveriae RK075. a ALE of U. vetiveriae on glycerol as sole carbon source. A single representative culture is shown. b Comparison of growth (squares, solid lines) and glycerol consumption (circles, dashed lines) and $\mathbf{c}$ itaconate (diamonds, solid lines) and malate (triangles, dashed lines) production for U. vetiveriae RK075 (black, closed symbols) and U. vetiveriae TZ1 (red, open symbols) on glycerol. Error bars indicate deviation from the mean $(n=2)$

25th re-inoculation. Investigation of the cultures after 21 rounds of re-inoculation revealed that only $U$. vetiveriae was still able to produce itaconic acid (Table 1). Apparently, itaconate production is detrimental to the fitness of these strains under the applied ALE conditions, leading to lower or completely abolished production after prolonged ALE. The putative natural functions of itaconate include the competition with other microbes by a drop in $\mathrm{pH}$ and the liberation of micronutrients through chelating properties [27], both not required under these laboratory conditions. However, itaconate production is not expected to occur as long as a nitrogen source is present. Possibly, an altered ALE strategy with elevated ammonium levels and re-inoculation at lower cell densities may avoid the loss of itaconate production during ALE. Another possibility would be the investigation of itaconic acid production for all evolved strains after each re-inoculation. Even though $U$. vetiveriae stopped itaconate production after the 25th re-inoculation during ALE, it was still able to produce considerable amounts of itaconate after 21 re-inoculations. The best single colony (U. vetiveriae TZ1) isolated from the 21 st re-inoculation, which corresponds to about 105 generations, produced $10.4 \pm 2.1 \mathrm{~g} \mathrm{~L}^{-1}$ itaconate within $384 \mathrm{~h}$ at a production rate of $0.03 \pm 0.01 \mathrm{~g} \mathrm{~L}^{-1} \mathrm{~h}^{-1}$ (Fig. 2c). In comparison, the reference strain (before ALE) produced $4.4 \pm 0.8 \mathrm{~g} \mathrm{~L}^{-1}$ at a rate of $0.01 \pm 0.00 \mathrm{~g} \mathrm{~L}^{-1} \mathrm{~h}^{-1}$ (Fig. 2c). Since the supplied amount of nitrogen was the same in both cultures and the final optical density was in the same range, this increase can actually be attributed to a higher specific production rate $\left(g_{\text {malate }} g_{\text {biomass }}^{-1} h^{-1}\right)$. Additionally, malate production in this strain was improved, reaching $26.6 \pm 4.7 \mathrm{~g} \mathrm{~L}^{-1}$ at a rate of $0.07 \pm 0.01 \mathrm{~g} \mathrm{~L}^{-1} \mathrm{~h}^{-1}$, whereas the reference produced $11.5 \pm 0.5 \mathrm{~g} \mathrm{~L}^{-1}$ at a rate of $0.03 \pm 0.00 \mathrm{~g} \mathrm{~L}^{-1} \mathrm{~h}^{-1}$. Although the itaconic acid titer of $U$. xerochloae in the initial screening was higher, we focused on the evolved $U$. vetiveriae strain for further investigation because morphological and physiological characteristics of $U$. xerochloae (e.g., filamentous growth) interfered with downstream analytics and reproducibility.

Since the clustered genes, responsible for itaconate production in $U$. maydis have been discovered recently [27], and the genome for $U$. vetiveriae was sequenced [55], we determined the presence of the itaconate cluster in this novel strain. Overall, proteins encoded in the $U$. vetiveriae cluster have $70-90 \%$ sequence similarity to their counterparts from $U$. maydis except for Rial, which shows only $44 \%$ sequence identity (Fig. 3). This indicates that itaconate production likely proceeds via the same pathway [27]. This similarity is further supported, by the 


U. vetiveriae RK075
genome

presence of 2-hydroxyparaconate in $U$. vetiveriae cultures, which is assumed to be a degradation product of itaconate [28], and the existence of the respective genes in the cluster.

\section{Medium optimization elevates itaconate production with $U$. vetiveriae TZ1}

Even though production values both for malic acid, as well as itaconic acid were improved by ALE, the reached titers and production rates are still low compared to published values [16, 28, 40, 48, 53]. To further improve production properties, medium optimization was performed. The influence of differing concentrations of medium components on microbial production processes for organic acids, biomass, and proteins has been shown consistently in the literature for different organisms, such as Aspergilli [14, 56-58], Ustilaginaceae [21, 59], and Corynebacterium glutamicum [60]. Additionally, the used concentration of nitrogen and the used nitrogen source itself (e.g., ammonium chloride, yeast extract, and peptone) drastically changed acid production in different organisms [16, 29, 40, 59]. Consequently, we tested changing concentrations of $\mathrm{NH}_{4} \mathrm{Cl}\left(0.8,1.6,3.2 \mathrm{~g} \mathrm{~L}^{-1}\right), \mathrm{FeSO}_{4}\left(3,13,53,103 \mathrm{mg} \mathrm{L}^{-1}\right)$, $\mathrm{KH}_{2} \mathrm{PO}_{4}\left(0.125,0.25,0.5,1 \mathrm{~g} \mathrm{~L}^{-1}\right)$, and $\mathrm{MgSO}_{4}(0.1,0.2$, $\left.0.5 \mathrm{~g} \mathrm{~L}^{-1}\right)$, while keeping the concentration of all other components in the MTM unaltered. Additionally, we used peptone $\left(2 \mathrm{~g} \mathrm{~L}^{-1}\right)$ or yeast extract $\left(2.4,4.8 \mathrm{~g} \mathrm{~L}^{-1}\right)$ instead of ammonium chloride. These two complex medium components contain 12.47 and $8.54 \%$ nitrogen, respectively, as determined by elemental analysis. Thus, the nitrogen (N) content of the different nitrogen sources was determined to correspond to $19 \mathrm{mM}\left(0.8 \mathrm{~g} \mathrm{~L}^{-1} \mathrm{NH}_{4} \mathrm{Cl}\right), 37 \mathrm{mM}$ (1.6 $\left.\mathrm{g} \mathrm{L}^{-1} \mathrm{NH}_{4} \mathrm{Cl}\right), 75 \mathrm{mM}\left(3.2 \mathrm{~g} \mathrm{~L}^{-1} \mathrm{NH}_{4} \mathrm{Cl}\right), 18 \mathrm{mM}$ (2.0 $\mathrm{g} \mathrm{L}^{-1}$ peptone), $15 \mathrm{mM}\left(2.4 \mathrm{~g} \mathrm{~L}^{-1}\right.$ yeast extract), and $0.29 \mathrm{mM}\left(4.8 \mathrm{~g} \mathrm{~L}^{-1}\right.$ yeast extract).

Altered concentrations of $\mathrm{FeSO}_{4}, \mathrm{KH}_{2} \mathrm{PO}_{4}$, and $\mathrm{MgSO}_{4}$ did not change organic acid production with $U$. vetiveriae TZ1 (data not shown). Changing the nitrogen concentration and source itself, however, drastically improved growth, glycerol uptake, and organic acid production (Fig. 4).

As expected, a higher ammonium chloride concentration increased final $\mathrm{OD}_{600}$ and volumetric glycerol uptake rates. However, growth of $U$. vetiveriae was delayed, possibly due to higher stress levels resulting from high ammonium concentrations. This effect was previously observed using $U$. trichophora [41]. As expected, volumetric acid production rates improved with increasing $\mathrm{NH}_{4} \mathrm{Cl}$ concentrations, due to higher biomass concentrations. However, with $3.2 \mathrm{~g} \mathrm{~L}^{-1} \mathrm{NH}_{4} \mathrm{Cl}$, the final titer was reduced in comparison to $1.6 \mathrm{~g} \mathrm{~L}^{-1} \mathrm{NH}_{4} \mathrm{Cl}$. Even though in comparison to $0.8 \mathrm{~g} \mathrm{~L}^{-1} \mathrm{NH}_{4} \mathrm{Cl}$, the amount of supplied nitrogen was slightly lower for $2 \mathrm{~g} \mathrm{~L}^{-1}$ peptone, and $2.4 \mathrm{~g} \mathrm{~L}^{-1}$ yeast extract, itaconate production was greatly improved with the latter two $\mathrm{N}$ sources. In contrast to ammonium chloride, the use of these complex nitrogen sources resulted in an earlier onset of growth, consequently also resulting in an earlier production phase. Likely, yeast extract and peptone are less toxic to the cells in the initial growth stage, and their uptake and incorporation into biomass are energetically favorable. The uptake of di-, tri-, and possibly even oligopeptides is more efficient, since energy is spent for the uptake of one molecule, while several amino acids can be scavenged. The resulting surplus of energy leads to an overall improved biomass yield [61]. The highest itaconate titer of $34.7 \pm 2.5 \mathrm{~g} \mathrm{~L}^{-1}$ was reached with $4.8 \mathrm{~g} \mathrm{~L}^{-1}$ yeast extract produced at a rate of $0.09 \pm 0.01 \mathrm{~g} \mathrm{~L}^{-1} \mathrm{~h}^{-1}$. Simultaneously $46.2 \pm 1.4 \mathrm{~g} \mathrm{~L}^{-1}$ malate was produced.

\section{Product inhibition by itaconate is likely stronger than product inhibition by malate}

For malate production with $U$. trichophora TZ1, a drastic increase in production rate could be achieved in controlled bioreactors [41]. Hence, we also investigated itaconate production with $U$. vetiveriae TZ1 in fedbatch cultivations with $200 \mathrm{~g} \mathrm{~L}^{-1}$ initial glycerol. Using $3.2 \mathrm{~g} \mathrm{~L}^{-1} \mathrm{NH}_{4} \mathrm{Cl}$ or $5 \mathrm{~g} \mathrm{~L}^{-1}$ yeast extract resulted in a 

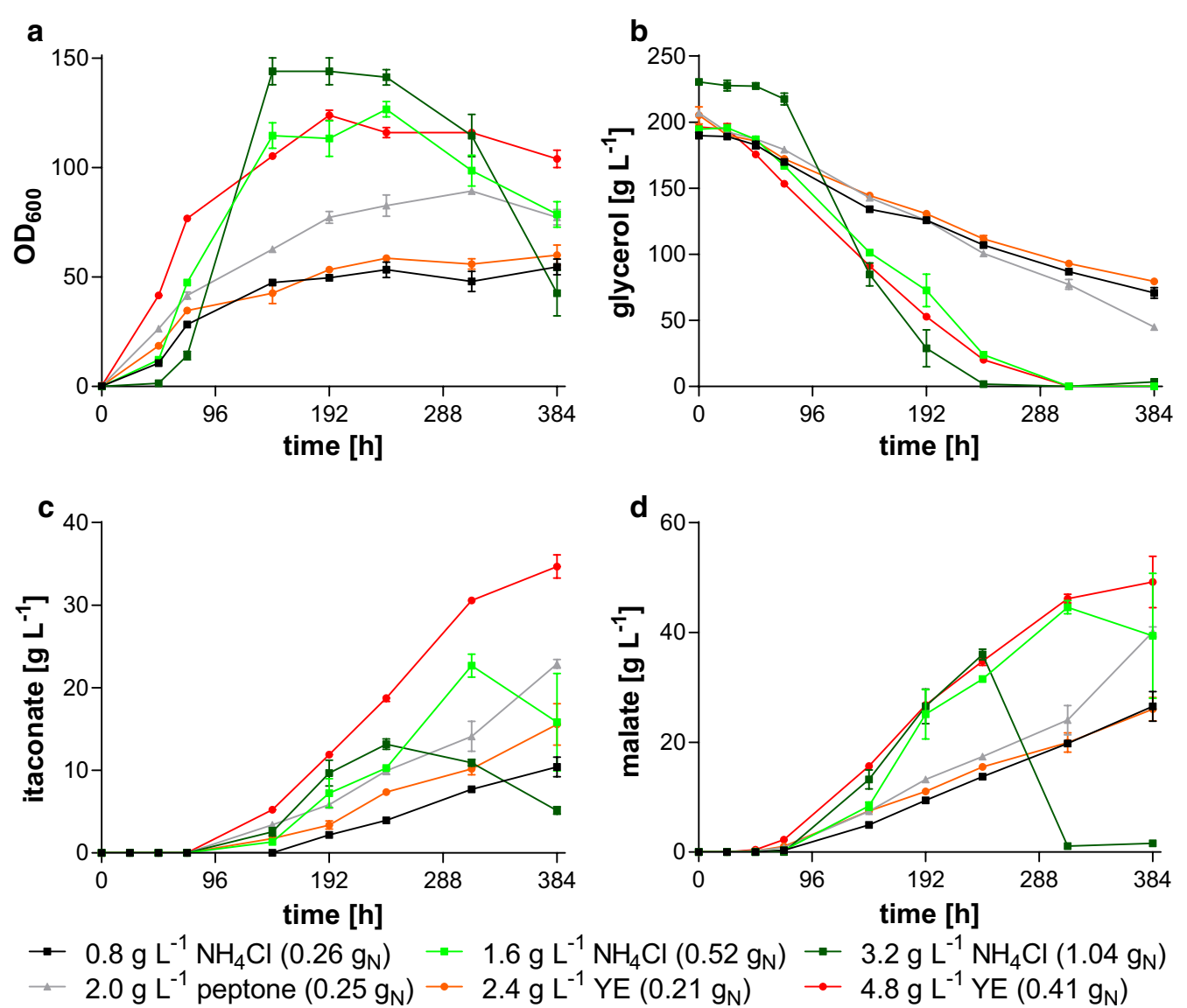

Fig. 4 Medium optimization for U. vetiveriae TZ1. a $\mathrm{OD}_{600}$, b glycerol concentration, $\mathbf{c}$ itaconate concentration, and $\mathbf{d}$ malate concentration for U. vetiveriae TZ1 cultivated in 24-deep well plates containing MTM with $200 \mathrm{~g} \mathrm{~L}^{-1}$ glycerol, $100 \mathrm{~g} \mathrm{~L}^{-1} \mathrm{CaCO}_{3}$ and different concentrations of $\mathrm{NH}_{4} \mathrm{Cl}$, yeast extract (YE) or peptone. Error bars indicate deviation from the mean $(n=3)$

production rate of $0.06 \pm 0.00 \mathrm{~g} \mathrm{~L}^{-1} \mathrm{~h}^{-1}$, which is similar to the values observed in 24-deep well plates (Fig. 5b; Table 2). Surprisingly, the titer (about $24 \mathrm{~g} \mathrm{~L}^{-1}$ ), was not increased for either culture, even though additional glycerol was fed throughout the fermentation. The experiments were repeated and the parameters were changed but in all bioreactor cultivations a titer of about $24 \mathrm{~g} \mathrm{~L}^{-1}$ itaconate could not be exceeded (data not shown). In $\mathrm{CaCO}_{3}$-buffered shake flasks, in contrast, higher concentrations were reached. This hints at product inhibition by itaconic acid concentrations above $24 \mathrm{~g} \mathrm{~L}^{-1}$.

We described this effect previously in the context of malic acid formation with $U$. trichophora $\mathrm{TZ1}$, where in $\mathrm{CaCO}_{3}$-buffered shake flasks and bioreactors, a concentration of about $200 \mathrm{~g} \mathrm{~L}^{-1}$ was reached, while in $\mathrm{NaOH}$ buffered bioreactors a concentration of about $140 \mathrm{~g} \mathrm{~L}^{-1}$ was limiting [41]. The concentration of dissolved malic acid in the culture broth of $\mathrm{CaCO}_{3}$-buffered cultures was determined to be about $15 \mathrm{~g} \mathrm{~L}^{-1}$ throughout the cultivation, consequently lowering the osmotic stress for the cells [40]. For itaconic acid, the concentration of dissolved acid in $\mathrm{CaCO}_{3}$-buffered water was determined to be about $11 \mathrm{~g} \mathrm{~L}^{-1}$ (Tim Massmann, personal communication) with precipitation of the residual itaconate as calcium itaconate, strengthening the hypothesis of product inhibition by higher dissolved itaconic acid concentrations in $\mathrm{NaOH}$-titrated bioreactors. Since also for $U$. vetiveriae TZ1 malic acid concentrations of up to $60.0 \pm 10.4 \mathrm{~g} \mathrm{~L}^{-1}$ were reached in bioreactors, product inhibition by itaconic acid seems to be stronger than by malic acid. Also, a synergistic effect of inhibition by malate and itaconate cannot be excluded. Consequently, for a feasible production process, in situ product removal would be needed and the amount of malate as a by-product must be reduced. The possibility of in situ product removal for itaconate production has been demonstrated, making continuous production processes with Ustilaginaceae a promising option [34,62]. Another possibility would be further ALE on higher itaconic acid concentrations in the medium, to obtain a strain which is 
less sensitive towards this product, provided that a loss of production can be avoided.

Apart from the observed product inhibition, the nitrogen source had a strong influence on fermentation performance. As expected, a lowered $\mathrm{NH}_{4} \mathrm{Cl}$ concentration $\left(1.6 \mathrm{~g} \mathrm{~L}^{-1} \mathrm{NH}_{4} \mathrm{Cl}\right)$ resulted in a lowered volumetric itaconate and malate production rate (Fig. 5b; Table 2), due to lower biomass formation (Fig. 5a). In contrast to results observed with $U$. trichophora TZ1 for malate production [41], 6.4 $\mathrm{g} \mathrm{L}^{-1} \mathrm{NH}_{4} \mathrm{Cl}$ combined with a doubled concentration for all other medium components resulted in neither rate nor titer improvement, rather reducing the growth rate and final $\mathrm{OD}_{600}$-values (Fig. 5a). In all, it seems that $U$. vetiveriae $\mathrm{TZ1}$ is less tolerant to higher
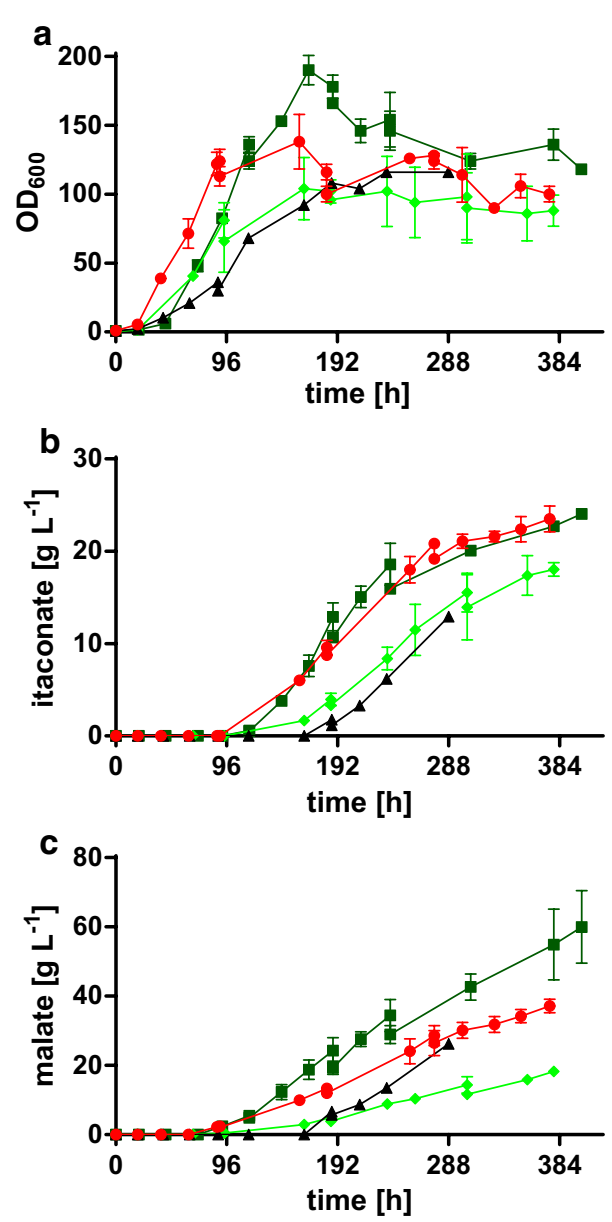

Fig. 5 Controlled batch cultivations of $U$. vetiveriae TZ1 with different nitrogen concentrations. $\mathbf{a} \mathrm{OD}_{600}, \mathbf{b}$ itaconate concentration, and $\mathbf{c}$ malate concentration, for cultures in MTM containing $200 \mathrm{~g} \mathrm{~L}^{-1}$ initial glycerol at $30^{\circ} \mathrm{C}$ and $\mathrm{pH} 6.5$ with DO kept at $80 \%$. Colors indicate different initial nitrogen concentrations: $5 \mathrm{~g} \mathrm{~L}^{-1}$ yeast extract (circles, red), $1.6 \mathrm{~g} \mathrm{~L}^{-1} \mathrm{NH}_{4} \mathrm{Cl}$ (diamonds, light green), $3.2 \mathrm{~g} \mathrm{~L}^{-1} \mathrm{NH}_{4} \mathrm{Cl}$ (squares, dark green), and $6.4 \mathrm{~g} \mathrm{~L}^{-1} \mathrm{NH}_{4} \mathrm{Cl}$ with doubled concentration of all medium components except glycerol (triangles, black). Error bars indicate deviation from the mean $(n=2)$ concentrations of ammonium or other medium salts than $U$. trichophora TZ1. In order to achieve higher cell densities and thus production rates, strains with improved tolerance towards higher salt concentrations can likely be isolated by additional ALE selection under ammonium stress, or an ammonium-fed process could be applied.

The use of $5 \mathrm{~g} \mathrm{~L}^{-1}$ yeast extract resulted in the same production values as the use of $3.2 \mathrm{~g} \mathrm{~L}^{-1} \mathrm{NH}_{4} \mathrm{Cl}$ (Table 2), even though only $40 \%$ of the nitrogen is supplied ( $30 \mathrm{mM}$ vs. $75 \mathrm{mM}$ ). Additionally, cultures grown in bioreactors with yeast extract showed an earlier onset of the growth and production phase, just as in shake flasks. However, the use of yeast extract in the production of bulk fermentation products is often a cost-prohibitive factor. Likely even with a higher concentration of $\mathrm{NH}_{4} \mathrm{Cl}$ or another nitrogen source, such as $\left(\mathrm{NH}_{4}\right) \mathrm{SO}_{4}$ of $\left(\mathrm{NH}_{4}\right) \mathrm{NO}_{3}$, the overall process would be more cost-effective. Cultivations with $U$. maydis using these nitrogen sources resulted in high acid titers compared to acidic nitrogen sources, such as $\mathrm{NH}_{4} \mathrm{H}_{2} \mathrm{PO}_{4}$ or $\mathrm{NH}_{4} \mathrm{Cl}$, even though the main effect was argued to result from higher final $\mathrm{pH}$ values in barely buffered shake flask cultivations [20]. Yet, these observations would also correspond to first results with $U$. vetiveriae $\mathrm{TZ1}$ cultivated in bioreactors at $\mathrm{pH} 4.5$ and 5.5 (data not shown). At $\mathrm{pH} 4.5$, no itaconate and malate production could be observed, while at pH 5.5 itaconate was still produced at a low titer of $8.0 \pm 0.8 \mathrm{~g} \mathrm{~L}^{-1}$. Notably, in this cultivation, no malate was produced, suggesting a strategy for single product formation.

Even though itaconate production could not be improved in bioreactors, malate production was elevated. With $3.2 \mathrm{~g} \mathrm{~L}^{-1} \mathrm{NH}_{4} \mathrm{Cl}$, the malate titer increased to $60.0 \pm 10.4 \mathrm{~g} \mathrm{~L}^{-1}$ produced within $403 \mathrm{~h}$ (Fig. 5c; Table 2). Just as for itaconate, malate production was reduced both with higher and lower $\mathrm{NH}_{4} \mathrm{Cl}$ concentrations. With yeast extract, malic acid production was improved compared to the production with $1.6 \mathrm{~g} \mathrm{~L}^{-1} \mathrm{NH}_{4} \mathrm{Cl}$, even though the contained nitrogen content is about $20 \%$ lower. These high values for malic acid underline the higher tolerance of Ustilaginaceae against malic acid compared to itaconic acid, even though, a specific production process for itaconic acid without by-product formation would be preferred.

\section{Metabolic engineering shifts organic acid production towards itaconate}

Product specificity and hence product yield on substrate are important factors in microbial production processes. The simultaneous production of several organic acids in one strain results in a lowered titer for the desired product. Additionally, product recovery is more complex with similar compounds in the medium [63]. Thus, a strain producing one organic acid with high specificity is desirable. The possibility to improve microbial organic acid 
Table 2 Characteristics of the bioconversion

\begin{tabular}{|c|c|c|c|c|}
\hline & Titer $\left(\mathrm{g} \mathrm{L}^{-1}\right)$ (itaconate) & Rate $\left(\mathrm{g} \mathrm{L}^{-1} \mathrm{~h}^{-1}\right)$ (itaconate) & Yield ( $g_{\text {ita }} g_{\text {gly }}^{-1}$ ) (itaconate) & Titer $\left(\mathrm{g} \mathrm{L}^{-1}\right)$ (malate) \\
\hline $5 \mathrm{~g} \mathrm{~L}^{-1} \mathrm{YE}$ & $23.5 \pm 1.4$ & $0.06 \pm 0.00$ & $0.08 \pm 0.02$ & $37.2 \pm 2.0$ \\
\hline $1.6 \mathrm{~g} \mathrm{~L}^{-1} \mathrm{NH}_{4} \mathrm{Cl}$ & $18.0 \pm 0.7$ & $0.05 \pm 0.00$ & $0.06 \pm 0.01$ & $18.3 \pm 1.3$ \\
\hline $3.2 \mathrm{~g} \mathrm{~L}^{-1} \mathrm{NH}_{4} \mathrm{Cl}$ & $24.1 \pm 0.2$ & $0.06 \pm 0.00$ & $0.07 \pm 0.00$ & $60.0 \pm 10.4$ \\
\hline $6.4 \mathrm{~g} \mathrm{~L}^{-1} \mathrm{NH}_{4} \mathrm{Cl}$ & $13.3 \pm 0.5$ & $0.05 \pm 0.00$ & $0.07 \pm 0.00$ & $26.5 \pm 0.4$ \\
\hline $4.8 \mathrm{~g} \mathrm{~L}^{-1} \mathrm{YE}$ (shake flask) & $34.7 \pm 2.5$ & $0.09 \pm 0.01$ & $0.18 \pm 0.01$ & $46.2 \pm 1.4$ \\
\hline
\end{tabular}

Comparison of titer, rate, and yield for itaconate and titer of the main by-product malate for different bioreactor cultivations and the best shake flask cultivation. \pm values indicate deviation from the mean ( $n=3$ for shake flask, $n=2$ for bioreactors)

production processes by overexpression of the specific underlying production pathways has been shown consistently for different organisms and products $[52,53$, 64-67]. In previous studies on itaconate production from glucose with $U$. maydis MB215, overexpression of the mitochondrial transporter $m t t 1$ and the regulator ria 1 of the itaconate gene cluster led to improved itaconate and reduced malic acid production [27, 68]. Additionally, the formation of the assumed degradation product of itaconate, 2-hydroxyparaconate, was influenced in the same way as itaconate production itself $[28,68]$. Thus, in order to investigate whether it is possible to shift the product spectrum of $U$. vetiveriae towards itaconate in a similar manner, we created mutants of $U$. vetiveriae RK075 overexpressing either $m t t 1$ or ria1 from $U$. maydis MB215. For overexpression, we used a plasmid (pUMa43 Otefgfp-nos-cbx) for $U$. maydis, which confers resistance to carboxin by site-specific integration into the $i p^{\mathrm{R}}$-locus. Previously we showed that this plasmid can also confer resistance to carboxin in other Ustilaginaceae, such as $U$. trichophora, even though site specificity is not given. Additionally, all contained genetic elements, such as promoter and terminator, were functional in other Ustilaginaceae [52].

Cultivation of the $U$. vetiveriae overexpression mutants in 24-deep well plates containing MTM with $0.8 \mathrm{~g} \mathrm{~L}^{-1}$
$\mathrm{NH}_{4} \mathrm{Cl}, 200 \mathrm{~g} \mathrm{~L}^{-1}$ glycerol, and $100 \mathrm{~g} \mathrm{~L}^{-1} \mathrm{CaCO}_{3}$ resulted in a 1.5-fold and twofold increased itaconate production after $384 \mathrm{~h}$ for $U$. vetiveriae overexpressing $m t t 1$ and ria 1 , respectively (Fig. 6a). Simultaneously, malate production was reduced to $75 \%$ for $m t t 1$ and $59 \%$ for rial (Fig. $6 \mathrm{~b}$ ). Also the values for 2-hydroxyparaconate production were in line with the previously published results. This opens up further steps for improvement by deletion of the respective genes, since 2-hydroxyparaconate is an assumed degradation product of itaconate $[28,68]$.

This shift of organic acid production in favor of itaconate upon overexpression of either ria1 or $m t t 1$ is comparable to the one in $U$. maydis MB215 both on glucose [68] and glycerol (data not shown). From these results, it was assumed that the mitochondrial transporter Mtt1 is the bottleneck of itaconate production in $U$. maydis, which can be overcome directly by overexpression of $m t t 1$, or indirectly by overexpression of the regulator ria1 [68]. This bottleneck seems also to be present in $U$. vetiveriae and can be overcome by single overexpression of $m t t 1$ or ria1 from $U$. maydis MB215. These data indicate that not only the above-mentioned $70-90 \%$ sequence similarity for the proteins in the itaconate cluster of $U$. vetiveriae and $U$. maydis are sufficient for efficient heterologous expression but also the regulator of the itaconate cluster from $U$. maydis (ria1), in spite of a low similarity of
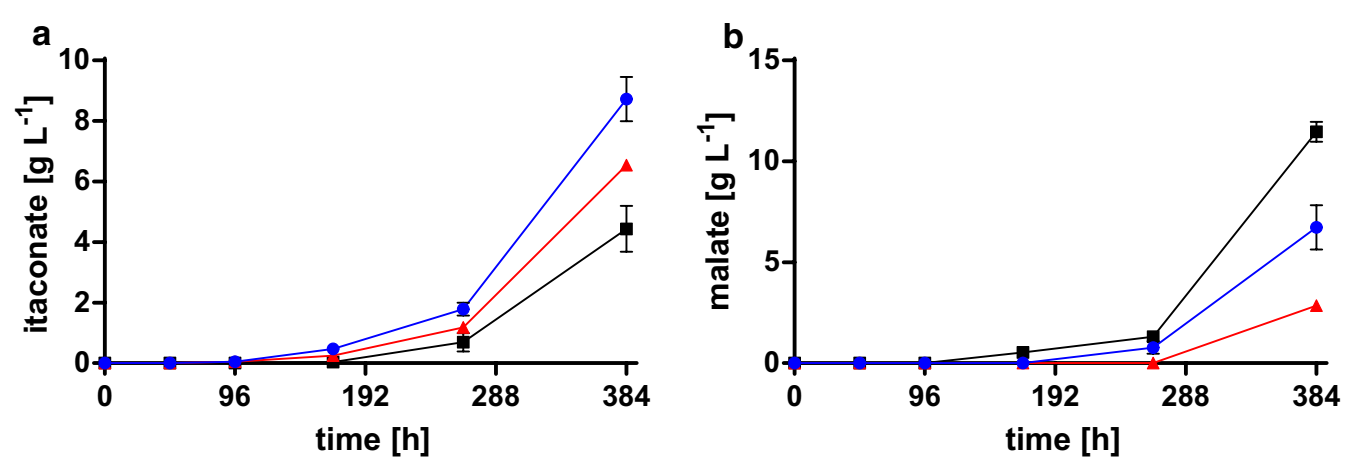

Fig. 6 Overexpression of rial and $m t t 1$ in $U$. vetiveriae RK075. a Itaconate and $\mathbf{b}$ malate concentration after $384 \mathrm{~h}$ cultivation for $U$. vetiveriae RK075 overexpressing $\mathrm{mtt} 1$ (red), rial (blue), and U. vetiveriae RK075 (black) cultivatedin 24-deep well plates containing MTM with $200 \mathrm{~g} \mathrm{~L}^{-1} \mathrm{glycerol}$, $100 \mathrm{~g} \mathrm{~L}^{-1} \mathrm{CaCO}_{3}$, and $0.8 \mathrm{~g} \mathrm{~L}^{-1} \mathrm{NH}_{4} \mathrm{Cl}$. Error bars indicate deviation from the mean $(n=3)$ 
$44 \%$, is functional in $U$. vetiveriae and even other Ustilago strains, such as $U$. xerochloae (data not shown). In all, we were able to present $U$. vetiveriae TZ1 as promising production organism for itaconic acid from glycerol. First metabolic engineering attempts revealed the possibility to improve the product specificity by up-regulation of itaconate production from glycerol.

\section{Conclusions}

Valorization of glycerol from biodiesel production has been a research focus for many years. The identified and improved $U$. vetiveriae strain TZ1 contributes a novel strategy, since it is able to produce high titers of organic acids from glycerol. Concentrations above $25 \mathrm{~g} \mathrm{~L}^{-1}$ itaconate seem to be inhibiting, consequently lowering the reached titers in $\mathrm{NaOH}$-titrated bioreactors compared to $\mathrm{CaCO}_{3}$-buffered shake flasks, in which the product precipitates as calcium salt. The use of
$\mathrm{CaCO}_{3}$ as buffering agent in bioreactors might help to overcome this limitation. Additionally, single-gene metabolic engineering allowed a reduction in the main byproduct malate, thereby significantly increasing product specificity. Multi gene target metabolic engineering in the evolved $U$. vetiveriae TZ1 harbors huge potential to further improve strain performance. The here described workflow from primary screening, ALE, and medium optimization all the way to first metabolic engineering allows a rapid evaluation of novel host strains for the production of valuable products from alternative carbon sources.

\section{Methods}

\section{Strains and culture conditions}

The 76 strains belonging to the family Ustilaginaceae screened by Zambanini et al. [40] plus 50 additional strains were screened in this study (Table 3 ).

Table 3 Screened strains from the family Ustilaginaceae with final glycerol concentration

\begin{tabular}{|c|c|c|c|c|c|}
\hline Name & Origin & Gly $\left(\mathrm{g} \mathrm{L}^{-1}\right)$ & Ita $\left(g^{-1}\right)$ & Mal $\left(g^{-1}\right)$ & Suc $\left(g^{-1}\right)$ \\
\hline Cintractia axicola BRIP 26922a & Queensland Plant Pathology Herbarium, Australia & 55 & & & \\
\hline S. modestum BRIP 26928a & Queensland Plant Pathology Herbarium, Australia & 51 & & & \\
\hline C. lipocarphae BRIP 26925a & Queensland Plant Pathology Herbarium, Australia & 51 & & & \\
\hline U. porosa BRIP 26920a & Queensland Plant Pathology Herbarium, Australia & 45 & & & \\
\hline U. maydis RK 212 & {$[70]$} & 42 & & & \\
\hline U. lituana BRIP 46795a & Queensland Plant Pathology Herbarium, Australia & 42 & & & \\
\hline U. avenae & Centraalbureau Voor Schimmelcultures 131466 & 41 & & & \\
\hline U. maydis Nr. 484 & American Type Culture Collection 22903 & 40 & & & \\
\hline S. caledonicum BRIP 28043a & Queensland Plant Pathology Herbarium, Australia & 40 & & & \\
\hline U. maydis DSM 14603 & $\begin{array}{l}\text { Deutsche Sammlung von Mikroorganismen und } \\
\text { Zellkulturen (DSMZ) }\end{array}$ & 40 & & & \\
\hline U. maydis Nr. 213 & Prof. M. Bölker, Philipps University Marburg, Germany & 39 & & & \\
\hline U. maydis DSM 3121 & $\begin{array}{l}\text { Deutsche Sammlung von Mikroorganismen und } \\
\text { Zellkulturen (DSMZ) }\end{array}$ & 37 & & & \\
\hline U. maydis Nr. 477 a1bP & American Type Culture Collection 22895 & 34 & & & \\
\hline U. maydis Nr. 488 & American Type Culture Collection 22907 & 34 & & & \\
\hline U. cynodontis NBRC 7530 & NITE Biological Resource Center & 34 & & & \\
\hline U. maydis Nr. $466 \mathrm{a} 1 \mathrm{bE}$ & American Type Culture Collection 22885 & 33 & & & \\
\hline U. maydis Nr. 483 & American Type Culture Collection 22902 & 33 & & & \\
\hline U. maydis Nr. 197 & Prof. M. Bölker, Philipps University Marburg, Germany & 32 & & & \\
\hline U. rabenhorstiana NBRC 8995 & NITE Biological Resource Center & 31 & & & \\
\hline U. maydis Nr. 465 a1bD & American Type Culture Collection 22884 & 30 & & & \\
\hline U. maydis Nr. 206 & Prof. M. Bölker, Philipps University Marburg, Germany & 30 & & & \\
\hline U. maydis Nr. 467 a1bF & American Type Culture Collection 22886 & 30 & & & \\
\hline U. maydis Nr. 482 & American Type Culture Collection 22901 & 29 & & & \\
\hline U. cynodontis NBRC 9727 & NITE Biological Resource Center & 29 & & & \\
\hline U. maydis Nr. 204 & Prof. M. Bölker, Philipps University Marburg, Germany & 29 & & & \\
\hline U. maydis Nr. 462 a1bA & Prof. M. Bölker, Philipps University Marburg, Germany & 29 & & & \\
\hline U. filiformis UMa701 & Centraalbureau Voor Schimmelcultures 131469 & 29 & & & \\
\hline U. maydis FB1 a1b1 & Banuett \& Herskowitz, 1989, Minnesota USA & 28 & & & \\
\hline U. maydis RK 134 & {$[70]$} & 28 & & & \\
\hline
\end{tabular}


Table 3 continued

\begin{tabular}{|c|c|c|c|c|c|}
\hline Name & Origin & Gly $\left(g^{-1}\right)$ & $\operatorname{Ita}\left(\mathrm{g} \mathrm{L}^{-1}\right)$ & Mal $\left(\mathrm{g} \mathrm{L}^{-1}\right)$ & Suc $\left(g^{-1}\right)$ \\
\hline U. maydis Nr. 485 & American Type Culture Collection 22904 & 28 & & & \\
\hline S. tumiforme BRIP 26919a & Queensland Plant Pathology Herbarium, Australia & 28 & 0.9 & 0.0 & 0.0 \\
\hline U. maydis RK 215 & {$[70]$} & 27 & & & \\
\hline U. maydis Nr. 489 & American Type Culture Collection 22908 & 26 & & & \\
\hline U. maydis Nr. 470 a1bl & Prof. M. Bölker, Philipps University Marburg, Germany & 25 & & & \\
\hline U. maydis RK 123 & {$[70]$} & 25 & & & \\
\hline U. maydis Nr. 198 & Prof. M. Bölker, Philipps University Marburg, Germany & 25 & & & \\
\hline U. maydis Nr. 207 & Prof. M. Bölker, Philipps University Marburg, Germany & 24 & & & \\
\hline S. cruentum UMa920 MAT1 & Centraalbureau Voor Schimmelcultures 133249 & 24 & & & \\
\hline U. cynodontis NBRC 9758 & NITE Biological Resource Center & 23 & & & \\
\hline U. maydis RK 122 & {$[70]$} & 23 & & & \\
\hline U. maydis Nr. 490 & American Type Culture Collection 22909 & 23 & & & \\
\hline U. hordei Uh4875-4 Mat1 & {$[71]$} & 23 & & & \\
\hline U. maydis Nr. 200 & Prof. M. Bölker, Philipps University Marburg, Germany & 22 & & & \\
\hline U. maydis Nr. 208 & Prof. M. Bölker, Philipps University Marburg, Germany & 22 & & & \\
\hline U. maydis Nr. 487 & American Type Culture Collection 22906 & 21 & & & \\
\hline U. maydis Nr. 195 & Prof. M. Bölker, Philipps University Marburg, Germany & 21 & & & \\
\hline U. maydis MB215 & $\begin{array}{l}\text { Deutsche Sammlung von Mikroorganismen und } \\
\text { Zellkulturen (DSMZ) DSM } 17144\end{array}$ & 20 & & & \\
\hline U. maydis Nr. 209 & Prof. M. Bölker, Philipps University Marburg, Germany & 20 & & & \\
\hline U. maydis RK 213 & {$[70]$} & 20 & & & \\
\hline S. consanguineum & Centraalbureau Voor Schimmelcultures 131456 & 19 & & & \\
\hline U. maydis Nr. 478 a1bQ & American Type Culture Collection 22896 & 19 & & & \\
\hline U. maydis RK 214 & {$[70]$} & 19 & & & \\
\hline U. maydis Nr. 212 & Prof. M. Bölker, Philipps University Marburg, Germany & 19 & & & \\
\hline U. maydis Nr. 215 & Prof. M. Bölker, Philipps University Marburg, Germany & 19 & & & \\
\hline U. maydis Nr. 214 & Prof. M. Bölker, Philipps University Marburg, Germany & 18 & & & \\
\hline U. maydis Nr. 205 & Prof. M. Bölker, Philipps University Marburg, Germany & 18 & & & \\
\hline U. maydis Nr. 463 a1bB & American Type Culture Collection 22882 & 18 & & & \\
\hline U. maydis Nr. 481 & American Type Culture Collection 22900 & 18 & & & \\
\hline U. maydis Nr. 196 & Prof. M. Bölker, Philipps University Marburg, Germany & 17 & & & \\
\hline U. maydis Nr. 199 & Prof. M. Bölker, Philipps University Marburg, Germany & 17 & & & \\
\hline U. maydis Nr. 492 & American Type Culture Collection 22911 & 17 & & & \\
\hline U. maydis Nr. 201 & Prof. M. Bölker, Philipps University Marburg, Germany & 17 & & & \\
\hline U. maydis RK 139 & {$[70]$} & 16 & & & \\
\hline C. lipocarphae BRIP 26927a & Queensland Plant Pathology Herbarium, Australia & 15 & & & \\
\hline U. maydis Nr. 469 a1bH & American Type Culture Collection 18604 & 14 & & & \\
\hline U. maydis Nr. 479 a $1 \mathrm{bR}$ & American Type Culture Collection 22897 & 14 & & & \\
\hline U. maydis Nr. 211 & Prof. M. Bölker, Philipps University Marburg, Germany & 14 & & & \\
\hline S. exsertum RK 033 & Centraalbureau Voor Schimmelcultures 131457 & 14 & & & \\
\hline U. schmidtiae BRIP 26906a & Queensland Plant Pathology Herbarium, Australia & 13 & & & \\
\hline U. maydis Nr. 491 & American Type Culture Collection 22910 & 13 & & & \\
\hline Ustanciosporium gigantosporum UMa706 & Centraalbureau Voor Schimmelcultures 131478 & 12 & & & \\
\hline Cintractia sp. BRIP $60413 a$ & Queensland Plant Pathology Herbarium, Australia & 12 & & & \\
\hline U. maydis Nr. 480 & American Type Culture Collection 22899 & 12 & & & \\
\hline U. maydis Nr. 495 & American Type Culture Collection 221914 & 12 & & & \\
\hline U. maydis DSM 4500 & $\begin{array}{l}\text { Deutsche Sammlung von Mikroorganismen und } \\
\text { Zellkulturen (DSMZ) }\end{array}$ & 11 & & & \\
\hline U. maydis HB1990 & $\begin{array}{l}\text { Biotechnology And Information Research Network } \\
\text { AG, Zwingenberg, Germany }\end{array}$ & 11 & & & \\
\hline U. maydis Nr. 476 a1bO & American Type Culture Collection 22894 & 11 & & & \\
\hline
\end{tabular}


Table 3 continued

\begin{tabular}{|c|c|c|c|c|c|}
\hline Name & Origin & Gly $\left(g^{-1}\right)$ & $\operatorname{Ita}\left(\mathrm{g} \mathrm{L}^{-1}\right)$ & Mal $\left(\mathrm{g} \mathrm{L}^{-1}\right)$ & Suc $\left(g^{-1}\right)$ \\
\hline S. setariae BRIP 26910a & Queensland Plant Pathology Herbarium, Australia & 10 & & & \\
\hline C. sp. BRIP 60422a & Queensland Plant Pathology Herbarium, Australia & 10 & & & \\
\hline U. maydis Nr. 202 & Prof. M. Bölker, Philipps University Marburg, Germany & 8 & & & \\
\hline M. spermophorus BRIP 60430a & Queensland Plant Pathology Herbarium, Australia & 7 & & & \\
\hline M. spermophorus BRIP 60448a & Queensland Plant Pathology Herbarium, Australia & 7 & & & \\
\hline S. scitamineum UMa698, Sscl4, JS109, MAT1 & Centraalbureau Voor Schimmelcultures 131462 & 7 & & & \\
\hline S. ovarium BRIP 26909a & Queensland Plant Pathology Herbarium, Australia & 6 & & & \\
\hline S. themedae BRIP 26917a & Queensland Plant Pathology Herbarium, Australia & 6 & & & \\
\hline S. aristidicola BRIP 26930a & Queensland Plant Pathology Herbarium, Australia & 6 & & & \\
\hline U. maydis Nr. 471 a1bJ & American Type Culture Collection 22889 & 5 & & & \\
\hline U. cynodontis BRIP 28040a & Queensland Plant Pathology Herbarium, Australia & 5 & & & \\
\hline U. maydis Nr. 203 & Prof. M. Bölker, Philipps University Marburg, Germany & 4 & & & \\
\hline S. walkeri RK 031 & Centraalbureau Voor Schimmelcultures 131464 & 4 & & & \\
\hline A. heteropogonicola BRIP $60896 a$ & Queensland Plant Pathology Herbarium, Australia & 3 & & & \\
\hline C. mitchellii BRIP 26923a & Queensland Plant Pathology Herbarium, Australia & 2 & & & \\
\hline U. maydis FB2 a2b2 & Banuett \& Herskowitz, 1989, Minnesota USA & 2 & & & \\
\hline Anthracocystis sehimatis BRIP 60890a & Queensland Plant Pathology Herbarium, Australia & 2 & 0.0 & 0.0 & 0.0 \\
\hline U. maydis Nr. 474 a1bM & American Type Culture Collection 22892 & 2 & & & \\
\hline P. antarctica NBRC 10260 & NITE Biological Resource Center & 1 & & & \\
\hline A. bothriochloae BRIP 60901 a & Queensland Plant Pathology Herbarium, Australia & 1 & 0.0 & 0.0 & 0.0 \\
\hline U. cynodontis UMa709 & Centraalbureau Voor Schimmelcultures 131467 & 1 & & & \\
\hline S. iseilematis-ciliati BRIP 60429a & Queensland Plant Pathology Herbarium, Australia & 0 & & & \\
\hline M. ordensis BRIP 26904a & Queensland Plant Pathology Herbarium, Australia & 0 & 1.0 & 0.0 & 0.0 \\
\hline U. curta BRIP 26929a & Queensland Plant Pathology Herbarium, Australia & 0 & & & \\
\hline S. lanigeri BRIP 27609a & Queensland Plant Pathology Herbarium, Australia & 0 & 1.0 & 0.0 & 0.0 \\
\hline U. maydis Nr. 473 a $1 \mathrm{bL}$ & American Type Culture Collection 22891 & 0 & & & \\
\hline M. eriachnes RK 028 & Centraalbureau Voor Schimmelcultures 131454 & 0 & & & \\
\hline U. trichophora RK089 & Centraalbureau Voor Schimmelcultures 131473 & 0 & & & \\
\hline U. vetiveriae RK 075 & Centraalbureau Voor Schimmelcultures 131474 & 0 & 0.6 & 0.7 & 0.2 \\
\hline U. xerochloae UMa702 & Centraalbureau Voor Schimmelcultures 131476 & 0 & 0.2 & 1.7 & 0.0 \\
\hline P. hubeiensis NBRC 105053 & NITE Biological Resource Center & 0 & 1.0 & 0.0 & 0.0 \\
\hline P. hubeiensis NBRC 105054 & NITE Biological Resource Center & 0 & 0.7 & 0.0 & 0.0 \\
\hline P. hubeiensis NBRC 105055 & NITE Biological Resource Center & 0 & 0.7 & 0.0 & 0.0 \\
\hline U. trichophora NBRC 100155 & NITE Biological Resource Center & 0 & 2.2 & 0.0 & 0.7 \\
\hline U. trichophora NBRC 100156 & NITE Biological Resource Center & 0 & 1.8 & 0.0 & 0.7 \\
\hline U. trichophora NBRC 100157 & NITE Biological Resource Center & 0 & 1.5 & 0.0 & 0.5 \\
\hline U. trichophora NBRC 100158 & NITE Biological Resource Center & 0 & 0.0 & 0.0 & 0.0 \\
\hline U. trichophora NBRC 100159 & NITE Biological Resource Center & 0 & 1.4 & 0.0 & 0.4 \\
\hline U. trichophora NBRC 100160 & NITE Biological Resource Center & 0 & 2.1 & 0.0 & 0.3 \\
\hline P. tsukubaensis NBRC 1940 & NITE Biological Resource Center & 0 & 0.8 & 0.1 & 0.0 \\
\hline M. mackinlayi BRIP 52549a & Queensland Plant Pathology Herbarium, Australia & 0 & 1.1 & 0.0 & 0.0 \\
\hline S. cenchri-elymoidis BRIP 26491a & Queensland Plant Pathology Herbarium, Australia & 0 & 1.7 & 0.0 & 0.0 \\
\hline S. bothriochloae BRIP 26908a & Queensland Plant Pathology Herbarium, Australia & 0 & & & \\
\hline U. triodiae BRIP 26907a & Queensland Plant Pathology Herbarium, Australia & 0 & & & \\
\hline M. tubiformis BRIP 60434a & Queensland Plant Pathology Herbarium, Australia & 0 & 0.0 & 0.0 & 0.0 \\
\hline U.xerochloae BRIP 60876a & Queensland Plant Pathology Herbarium, Australia & 0 & 2.7 & 0.0 & 0.2 \\
\hline S. iseilematis-ciliati BRIP $60887 a$ & Queensland Plant Pathology Herbarium, Australia & 0 & 0.0 & 2.5 & 0.0 \\
\hline A. caledonica BRIP 60892a & Queensland Plant Pathology Herbarium, Australia & 0 & 0.0 & 0.0 & 0.0 \\
\hline U. egenula BRIP 60884 a & Queensland Plant Pathology Herbarium, Australia & 0 & 0.0 & 0.0 & 0.0 \\
\hline
\end{tabular}


As standard medium, MTM was used according to Zambanini et al. containing $100 \mathrm{~g} \mathrm{~L}^{-1} \mathrm{CaCO}_{3}$ with differing concentrations of $\mathrm{FeSO}_{4}, \mathrm{MgSO}_{4}$, and $\mathrm{KH}_{2} \mathrm{PO}_{4}$ and differing concentrations of $\mathrm{NH}_{4} \mathrm{Cl}$, yeast extract, or peptone (see text for details) [40].

Adaptive laboratory evolution (for 62 days), medium optimization, preparation of pre-cultures, shake flask experiments, and batch cultivations were conducted as described previously [40, 41]. For batch cultivations, the $\mathrm{pH}$ was set to 6.5 and controlled by automatic addition of $10 \mathrm{M} \mathrm{NaOH}$.

\section{Analytical methods}

All experiments were performed in duplicates. Shown is the arithmetic mean of the duplicates. Error bars and \pm values indicate deviation from the mean.

Samples were treated as described previously [40, 41]. $\mathrm{OD}_{600}$ determination and HPLC analysis were performed as described previously [40]. Ammonium concentration was determined by a colorimetric assay according to Willis [69].

The nitrogen content of peptone and yeast extract was determined by Mikroanalytisches Laboratorium Kolbe $_{\text {(Nachf.) }}$ (Mülheim an der Ruhr, Germany).

\section{Cloning procedures}

For overexpression of rial and $m t t 1$, the overexpression constructs generated by Geiser et al. were used [27].

All cloning procedures were performed as described previously [52].

\section{Authors' contributions \\ $L M B$, NW, and GM conceived and designed the project. TZ, NW, JMB, and LMB designed experiments and analyzed results. TZ and NW wrote the manuscript with the help of LMB and JMB, TZ, HHT, EG, DM, SS, and JK performed the experiments. All authors read and approved the final manuscript.}

\section{Author details}

${ }^{1}$ Institute of Applied Microbiology-iAMB, Aachen Biology and Biotechnology-ABBt, RWTH Aachen University, Worringerweg 1, 52074 Aachen, Germany ${ }^{2}$ BRAIN AG, Darmstädter Straße 34, 64673 Zwingenberg, Germany.

\section{Acknowledgements}

We gratefully acknowledge BioEton for providing the glycerol. All BRIP isolates (2813-2851) were obtained from the culture collection of the Queensland Plant Pathology Herbarium (BRIP), Australia.

\section{Competing interests}

GM and JMB are paid employees of BRAIN AG. The authors declare that no financial or non-financial conflict of interest was present with regard to the results or interpretation of the reported experiments. Further, they declare that this does not alter the permission of unrestricted use, distribution, and reproduction in any medium, provided the original author and source are credited.

\section{Funding}

This study was partially funded by Biotechnology Research And Information Network AG (BRAIN AG) and by the German Federal Ministry of Education and Research (BMBF) as part of the Strategic Alliance ZeroCarbFP (Grant No. FKZ 031A217F). This work was performed as a part of the Cluster of Excellence "Tailor-Made Fuels from Biomass," which is funded by the Excellence Initiative of the German federal and state governments to promote science and research at German universities.

\section{Publisher's Note}

Springer Nature remains neutral with regard to jurisdictional claims in published maps and institutional affiliations.

Received: 17 January 2017 Accepted: 3 May 2017

Published online: 19 May 2017

\section{References}

1. Werpy T, Petersen GR, Aden A, Bozell J, Holladay J, White J, Manheim $A$, Eliot $D$, Lasure $L$, Jones $S$. Top value added chemicals from biomass. Volume 1 -results of screening for potential candidates from sugars and synthesis gas. Washington: Department of Energy; 2004.

2. Willke T, Vorlop KD. Biotechnological production of itaconic acid. Appl Microbiol Biotechnol. 2001;56(3-4):289-95.

3. Okabe M, Lies D, Kanamasa S, Park EY. Biotechnological production of itaconic acid and its biosynthesis in Aspergillus terreus. Appl Microbiol Biotechnol. 2009:84(4):597-606.

4. Klement T, Büchs J. Itaconic acid-a biotechnological process in change. Bioresour Technol. 2013:135:422-31.

5. Robert T, Friebel S. Itaconic acid - a versatile building block for renewable polyesters with enhanced functionality. 2016;18(10):2922-34.

6. Steiger MG, Wierckx N, Blank LM, Mattanovich D, Sauer M. Itaconic acidan emerging building block. In: Wittmann C, Liao JC, editors. Industrial biotechnology, products and processes. Weinheim, Germany: Wiley-VCH Verlag GmbH \& Co. KGaA; 2017.

7. WP 8.1 Determination of market potential for selected platform chemicals [http://www.bioconsept.eu/wp-content/uploads/BioConSepT_Marketpotential-for-selected-platform-chemicals_ppt1.pdf]. Accessed 21 May 2014.

8. Baup S. Ueber eine neue Pyrogen-Citronensäure, und über Benennung der Pyrogen-Säuren überhaupt. Eur J Organ Chem. 1836;19(1):29-38.

9. Shriner RL, Ford SG, Roll LJ. Itaconic anhydride and itaconic acid. Organ Synth. 1931;2(11):70.

10. Shriner RL, Ford SG, Roll LJ. Itaconic anhydride and itaconic acid. Organ Synth. 1943;2:368.

11. Kinoshita K. Über eine neue Aspergillus Art, Asp. itaconicus nov. spec. 1931;45(530):45-60.

12. Calam CT, Oxford AE, Raistrick H. Studies in the biochemistry of microorganisms -itaconic acid, a metabolic product of a strain of Aspergillus terreus. Biochem J. 1939;33(9):1488-95.

13. Kuenz A, Gallenmuller Y, Willke T, Vorlop KD. Microbial production of itaconic acid: developing a stable platform for high product concentrations. Appl Microbiol Biotechnol. 2012;96(5):1209-16.

14. Karaffa L, Kubicek CP. Aspergillus niger citric acid accumulation: do we understand this well working black box? Appl Microbiol Biotechnol. 2003;61(3):189-96.

15. Hevekerl A, Kuenz A, Vorlop KD. Filamentous fungi in microtiter plates-an easy way to optimize itaconic acid production with Aspergillus terreus. Appl Microbiol Biotechnol. 2014;98(16):6983-9.

16. Levinson WE, Kurtzman CP, Kuo TM. Production of itaconic acid by Pseudozyma antarctica NRRL Y-7808 under nitrogen-limited growth conditions. Enzyme Microb Tech. 2006;39(4):824-7.

17. Aurich ADI, Barth GPD, Bodinus C, Kreyss E, Specht R. Process for the biotechnological production of products. 2009; DE102008011854 A1.

18. Haskins RH, Thorn JA, Boothroyd B. Biochemistry of the Ustilaginales: X metabolic products of Ustilago zeae in submerged culture. Can J Microbiol. 1955;1(9):749-56.

19. Guevarra ED, Tabuchi T. Accumulation of itaconic, 2-hydroxyparaconic, itatartaric, and malic acids by strains of the genus Ustilago. Agric Biol Chem Tokyo. 1990;54(9):2353-8.

20. Guevarra ED, Tabuchi T. Production of 2-hydroxyparaconic and itatartaric acids by Ustilago cynodontis and simple recovery process of the acids. Agric Biol Chem Tokyo. 1990;54(9):2359-65.

21. Geiser E, Wiebach V, Wierckx N, Blank LM. Prospecting the biodiversity of the fungal family Ustilaginaceae for the production of value-added chemicals. BMC Fungal Biol Biotechnol. 2014;1:2.

22. Tabuchi T, Sugisawa T, Ishidori T, Nakahara T, Sugiyama J. Itaconic acid fermentation by a yeast belonging to the genus Candida. Agric Biol Chem. 1981;45(2):475-9. 
23. Kawamura D, Furuhashi M, Saito O, Matsui H. Production of itaconic acid by fermentation. Japan Patent. 1981.

24. Feldbrügge M, Kellner R, Schipper K. The biotechnological use and potential of plant pathogenic smut fungi. Appl Microbiol Biotechnol. 2013;97(8):3253-65.

25. Bölker M, Basse CW, Schirawski J. Ustilago maydis secondary metabolism — from genomics to biochemistry. Fungal Genet Biol. 2008;45:88-93.

26. Kirk PM, Ainsworth GC, Bisby GR. Ainsworth and Bisby's dictionary of the fungi. 10th ed. Wallingford: C.A.B. International; 2008.

27. Geiser E, Przybilla SK, Friedrich A, Buckel W, Wierckx N, Blank LM, Bölker M. Ustilago maydis produces itaconic acid via the unusual intermediate trans-aconitate. Microb Biotechnol. 2016;9(1):116-26.

28. Geiser E, Przybilla SK, Engel M, Kleineberg W, Buttner L, Sarikaya E, Hartog TD, Klankermayer J, Leitner W, Bolker M, et al. Genetic and biochemical insights into the itaconate pathway of Ustilago maydis enable enhanced production. Metab Eng. 2016. doi:10.1016/j.ymben.2016.10.006.

29. Maassen N, Panakova M, Wierckx N, Geiser E, Zimmermann M, Bölker M, Klinner U, Blank LM. Influence of carbon and nitrogen concentration on itaconic acid production by the smut fungus Ustilago maydis. Eng Life Sci. 2013;14(2):129-34.

30. Jeya M, Lee KM, Tiwari MK, Kim JS, Gunasekaran P, Kim SY, Kim IW, Lee JK. Isolation of a novel high erythritol-producing Pseudozyma tsukubaensis and scale-up of erythritol fermentation to industrial level. Appl Microbiol Biotechnol. 2009;83(2):225-31.

31. Moon HJ, Jeya M, Kim IW, Lee JK. Biotechnological production of erythritol and its applications. Appl Microbiol Biotechnol. 2010;86(4):1017-25.

32. Liu YB, Koh CMJ, Ji LH. Bioconversion of crude glycerol to glycolipids in Ustilago maydis. Bioresour Technol. 2011;102(4):3927-33.

33. Spoeckner S, Wray V, Nimtz M, Lang S. Glycolipids of the smut fungus Ustilago maydis from cultivation on renewable resources. Appl Microbiol Biotechnol. 1999:51(1):33-9.

34. Carstensen F, Klement T, Büchs J, Melin T, Wessling M. Continuous production and recovery of itaconic acid in a membrane bioreactor. Bioresour Technol. 2013;137:179-87.

35. Gunther M, Grumaz C, Lorenz S, Stevens P, Lindemann E, Hirth T, Sohn K, Zibek S, Rupp S. The transcriptomic profile of Pseudozyma aphidis during production of mannosylerythritol lipids. Appl Microbiol Biotechnol. 2015:99(3):1375-88.

36. Cano-Canchola C, Acevedo L, Ponce-Noyola P, Flores-Martinez A, Flores-Carreon A, Leal-Morales CA. Induction of lytic enzymes by the interaction of Ustilago maydis with Zea mays tissues. Fungal Genet Biol. 2000;29(3):145-51.

37. Couturier M, Navarro D, Olive C, Chevret D, Haon M, Favel A, LesageMeessen L, Henrissat B, Coutinho PM, Berrin JG. Post-genomic analyses of fungal lignocellulosic biomass degradation reveal the unexpected potential of the plant pathogen Ustilago maydis. Bmc Genom. 2012;13:57.

38. Geiser E, Wierckx N, Zimmermann M, Blank LM. Identification of an endo1,4-beta-xylanase of Ustilago maydis. BMC Biotechnol. 2013;13:59.

39. Geiser E, Reindl M, Blank LM, Feldbrugge M, Wierckx N, Schipper K. Activating intrinsic carbohydrate-active enzymes of the smut fungus Ustilago maydis for the degradation of plant cell wall components. Appl Environ Microbiol. 2016:82(17):5174-85.

40. Zambanini T, Sarikaya E, Kleineberg W, Buescher JM, Meurer G, Wierckx $\mathrm{N}$, Blank LM. Efficient malic acid production from glycerol with Ustilago trichophora TZ1. Biotechnol Biofuels. 2016;9:67.

41. Zambanini T, Kleineberg W, Sarikaya E, Buescher JM, Meurer G, Wierckx $\mathrm{N}$, Blank LM. Enhanced malic acid production from glycerol with highcell-density Ustilago trichophora TZ1 cultivations. Biotechnol Biofuels. 2016:9:135.

42. Blank LM, Wierckx N, Zambanini T, Sarikaya E, Buescher JM, Meurer G. Process for the production of malate. 2016(IB2015/059817).

43. Bozell JJ, Petersen GR. Technology development for the production of biobased products from biorefinery carbohydrates-the U.S. Department of Energy's "Top 10" revisited. Green Chem. 2010;12(4):539-54.

44. Anand P, Saxena RK. A comparative study of solvent-assisted pretreatment of biodiesel derived crude glycerol on growth and 1,3-propanediol production from Citrobacter freundii. N Biotechnol. 2012;29(2):199-205.

45. Yang F, Hanna MA, Sun R. Value-added uses for crude glycerol-a byproduct of biodiesel production. Biotechnol Biofuels. 2012;5:13.
46. West TP. Crude glycerol: a feedstock for organic acid production by microbial bioconversion. J Microbial Biochem Technol. 2012;4:ii-ii. doi:10.4172/1948-5948.1000e106.

47. Duetz WA, Ruedi L, Hermann R, O'Connor K, Büchs J, Witholt B. Methods for intense aeration, growth, storage, and replication of bacterial strains in microtiter plates. Appl Environ Microbiol. 2000;66(6):2641-6.

48. Bonnarme P, Gillet B, Sepulchre AM, Role C, Beloeil JC, Ducroca C. Itaconate biosynthesis in Aspergillus terreus. J Bacteriol. 1995;177(12):3573-8.

49. Dragosits M, Mattanovich D. Adaptive laboratory evolution-principles and applications for biotechnology. Microb Cell Fact. 2013;12:64.

50. Sauer U. Evolutionary engineering of industrially important microbial phenotypes. Adv Biochem Eng Biotechnol. 2001;73:129-69.

51. González-Ramos D, de Vries AR, Grijseels SS, Berkum MC, Swinnen S, Broek M, Nevoigt E, Daran JM, Pronk JT, Maris AJ. A new laboratory evolution approach to select for constitutive acetic acid tolerance in Saccharomyces cerevisiae and identification of causal mutations. Biotechnol Biofuels. 2016;9(1):173.

52. Zambanini T, Tehrani HH, Geiser E, Sonntag CS, Buescher JM, Meurer G, Wierckx N, Blank LM. Metabolic engineering of Ustilago trichophora TZ1 for improved malic acid production. Metab Eng Commun. 2017:4:12-21.

53. Brown SH, Bashkirova L, Berka R, Chandler T, Doty T, McCall K, McCulloch M, McFarland S, Thompson S, Yaver D, et al. Metabolic engineering of Aspergillus oryzae NRRL 3488 for increased production of L-malic acid. Appl Microbiol Biotechnol. 2013;97(20):8903-12.

54. Knuf C, Nookaew I, Remmers I, Khoomrung S, Brown S, Berry A, Nielsen J. Physiological characterization of the high malic acid-producing Aspergillus oryzae strain 2103a-68. Appl Microbiol Biotechnol. 2014;98(8):3517-27.

55. Geiser E, Ludwig F, Zambanini T, Wierckx N, Blank LM. Draft genome sequences of itaconate-producing ustilaginaceae. Genome Announc. 2016;4(6):e01291.

56. Batti M, Schweiger L. Process for the production of itaconic acid. U.S. Patent. 1963.

57. Sanchez-Marroquin A, Carreno R, Ledezma M. Effect of trace elements on citric acid fermentation by Aspergillus niger. Appl Microbiol. 1970;20(6):888-92.

58. Li A, Pfelzer N, Zuijderwijk R, Punt P. Enhanced itaconic acid production in Aspergillus niger using genetic modification and medium optimization. BMC Biotechnol. 2012;12:57.

59. Klement T, Milker S, Jäger G, Grande PM, de Maria PD, Büchs J. Biomass pretreatment affects Ustilago maydis in producing itaconic acid. Microb Cell Fact. 2012;11:43.

60. Jeon JM, Rajesh T, Song E, Lee HW, Lee HW, Yang YH. Media optimization of Corynebacterium glutamicum for succinate production under oxygendeprived condition. J Microbiol Biotechnol. 2013;23(2):211-7.

61. Heyland J, Fu J, Blank LM, Schmid A. Carbon metabolism limits recombinant protein production in Pichia pastoris. Biotechnol Bioeng. 2011;108(8):1942-53.

62. Magalhães Al, de Carvalho JC, Ramírez ENM, Medina JDC, Soccol CR. Separation of itaconic acid from aqueous solution onto ion-exchange resins. J Chem Eng Data. 2016;61(1):430-7.

63. Amy HAM, Berovic M, Gluszca P, Kristiansen B, Krzystek L, Kubicek C, Ledakowicz S, Lesniak W, Mattey M, Papagianni M, et al. Citric acid biotechnology. e-Library: Taylor \& Francis; 2002.

64. Zelle RM, de Hulster E, van Winden WA, de Waard P, Dijkema C, Winkler AA, Geertman JM, van Dijken JP, Pronk JT, van Maris AJ. Malic acid production by Saccharomyces cerevisiae: engineering of pyruvate carboxylation, oxaloacetate reduction, and malate export. Appl Environ Microbiol. 2008;74(9):2766-77.

65. Yuzbashev TV, Yuzbasheva EY, Sobolevskaya TI, Laptev IA, Vybornaya TV, Larina AS, Matsui K, Fukui K, Sineoky SP. Production of succinic acid at low $\mathrm{pH}$ by a recombinant strain of the aerobic yeast Yarrowia lipolytica. Biotechnol Bioeng. 2010;107(4):673-82.

66. Chen X, Xu G, Xu N, Zou W, Zhu P, Liu L, Chen J. Metabolic engineering of Torulopsis glabrata for malate production. Metab Eng. 2013;19:10-6.

67. Blumhoff ML, Steiger MG, Mattanovich D, Sauer M. Targeting enzymes to the right compartment: metabolic engineering for itaconic acid production by Aspergillus niger. Metab Eng. 2013;19:26-32.

68. Geiser E. Itaconic acid production by Ustilago maydis, vol. 1. Aachen: Apprimus; 2015. 
69. Willis RB, Montgomery ME, Allen PR. Improved method for manual, colorimetry determination of total Kjeldahl nitrogen using salicylate. J Agric Food Chem. 1996;44(7):1804-7.

70. Kellner R. Der Einfluss sexueller Reproduktion und Virulenz auf die Evolution und Speziation der biotrophen Brandpilzfamilie Ustilaginaceae.

Dissertation. Germany: Ruhr-Universität Bochum; 2011.
71. Linning R, Lin D, Lee N, Abdennadher M, Gaudet D, Thomas P, Mills D, Kronstad JW, Bakkeren G. Marker-based cloning of the region containing the UhAvr1 avirulence gene from the basidiomycete barley pathogen Ustilago hordei. Genetics. 2004;166(1):99-111.
Submit your next manuscript to BioMed Central and we will help you at every step:

- We accept pre-submission inquiries

- Our selector tool helps you to find the most relevant journal

- We provide round the clock customer support

- Convenient online submission

- Thorough peer review

- Inclusion in PubMed and all major indexing services

- Maximum visibility for your research

Submit your manuscript at www.biomedcentral.com/submit
() Biomed Central 